Pesq. Vet. Bras. 28(5):253-259, maio 2008

\title{
Aspectos morfológicos do saco vitelino em roedores da subordem Hystricomorpha: paca (Agouti paca) e cutia (Dasyprocta aguti) ${ }^{1}$
}

\author{
Rogério Arcuri Conceição², Carlos Eduardo Ambrósio ${ }^{*}$, Daniele S. Martins ${ }^{3}$, \\ Ana Flávia Carvalho ${ }^{2}$, André Luis R. Franciolli ${ }^{3}$, Marcia Rita F. Machado ${ }^{5}$, \\ Moacir F. Oliveira ${ }^{4}$ e Maria Angélica Miglino ${ }^{3}$
}

\begin{abstract}
Conceição R.A., Ambrósio C.E., Martins D.S., Carvalho A.F., Franciolli A.L.R., Machado M.R.F., Oliveira M.F. \& Miglino M.A. 2008. [Morphological aspects of yolk sac from rodents of Hystricomorpha subordem: paca (Agouti paca) and agouti (Dasyprocta aguti).] Aspectos morfológicos do saco vitelino em dois roedores da subordem Hystricomorpha: paca (Agouti paca) e cutia (Dasyprocta aguti). Pesquisa Veterinária Brasileira 28(5):253-259. Setor de Anatomia dos Animais Domésticos e Silvestres, Departamento de Cirurgia, Faculdade de Medicina Veterinária e Zootecnia. Universidade de São Paulo, Cidade Universitária, Av. Prof. Dr. Orlando Marques de Paiva 87, São Paulo, SP 05508-900, Brazil. E-mail: ceambrosio@usp.br

The study aimed to characterize gross and microscopic features of the yolk sac in paca (Agouti paca) and agouti (Dasyprocta aguti) in early gestation. Fragments of the yolk sac of 3 paca and 3 agouti fetuses at early gestation were taken and processed for histological and ultrastructural analyses. Gross features of the vitelline placenta in both species showed its insertion over the main placenta surface and projections to the embryos/fetuses. Microscopically, the vitelline placenta was constituted by endoderm epithelium and mesenchyme, in which vitelline vessels are abundant. The ultrastructure of the samples showed that the visceral yolk sac of the paca was formed by endodermic cells with nuclei in the median region, and that the visceral yolk sac of the agouti was formed by nuclei arranged apically; other characteristic was the large number of mitochondrias, eletrodense vesicles with microvilosities We conclude that (1) the vitelline placenta of the two species presents insertion in the surface of the main placenta; (2) the vitelline placenta of paca rests on the Reichert's membrane, whereas the agouti vitelline placenta does not have this membrane; (3) the chorion and allantoic are fusioned; and (4) the chorioallantoic placenta and the yolk sac in both species are reversed and vascularized.
\end{abstract}

INDEX TERMS: Hystricomorpha, Agouti paca, Dasyprota aguti, yolk sac.

\footnotetext{
${ }^{1}$ Recebido em 22 de janeiro de 2008.

Aceito para publicação em 16 de maio de 2008.

2 Setor de Anatomia dos Animais Domésticos e Silvestres, Centro Universitário da Fundação de Ensino Octávio Bastos, Av. Octávio Bastos s/n, Jd. Nova São João, São João da Boa Vista, SP 13.870-000, Brasil.

3 Setor de Anatomia dos Animais Domésticos e Silvestres, Departamento de Cirurgia, Faculdade de Medicina Veterinária e Zootecnia (FMVZ), Universidade de São Paulo (USP), Av. Prof. Dr. Orlando Marques de Paiva 87, Cidade Universitária, São Paulo, SP 05508-900, Brasil. “Autor para correspondência: ceambrosio@usp.br

${ }^{4}$ Departamento de Ciências Animais, Universidade Federal Rural do Semi-Árido, BR 110 Km 47, Cx. Postal 137, Mossoró, RN 59625-900, Brasil.

${ }^{5}$ Departamento de Morfologia e Fisiologia Animal, Unesp-Jaboticabal, Via de Acesso Prof. Paulo Donato Castellane s/n, Jaboticabal, SP 14884900, Brasil.
}

RESUMO.- Este trabalho visou caracterizar macro e microscopicamente o saco vitelino em pacas (Agouti paca) e cutias (Dasyprocta aguti) no início de gestação. Três embriões/fetos de pacas e três de cutias foram utilizados para a análise do saco vitelino, durante as fases iniciais de gestação. Fragmentos do saco vitelino foram removidos do embrião/feto e rotineiramente processados para inclusão em parafina (técnica histológica rotineira) e em resina Spurr (análise ultra-estrutural). Macroscopicamente, a placenta vitelínica em ambas as espécies inseria-se na superfície da placenta principal, com suas margens projetando-se completamente sobre o embrião/fetos. $\mathrm{Na}$ microscopia de luz, a placenta vitelínica apresentava-se constituída pelo epitélio endodérmico e um mesenquima 
com inúmeros vasos vitelínicos. Ultraestruturalmente, a placenta vitelínica visceral da paca era formada por células endodérmicas com núcleos na região mediana e da cutia por núcleos dispostos apicalmente; outra característica foi o grande número de mitocôndrias, vesículas de conteúdo eletrodenso e com microvilosidades. Com base nos resultados concluímos, que (1) a placenta vitelínica das duas espécies apresenta inserção na superfície da placenta principal; (2) a placenta vitelínica de paca se apóia na membrana de Reichert, diferentemente da cutia, que não possui tal membrana; (3) o cório e alantóide apresentam-se fusionados, formando a placenta corioalantoídea; e (4) o saco vitelino em ambas as espécies é invertido e vascularizado.

TERMOS DE INDEXAÇÃO: Hystricomorpha, Agouti paca, Dasyprocta aguti, saco vitelino.

\section{INTRODUÇÃO}

Os roedores são animais que oferecem uma extraordinária variedade de adaptações ecológicas, suportando os mais diversos tipos de climas e altitudes, podendo com isso apresentar grande diversidade funcional. No geral, esses animais apresentam tamanhos e formato de dentição característico devido ao desprovimento de dentes caninos que, aliados ao aspecto geral da maioria das formas, os tornam facilmente reconhecíveis. Além disto, vivem em diferentes hábitats, podendo expressar diferentes adaptações biológicas (Moojen 1962).

A paca (Agouti paca), depois da capivara, é o maior roedor da região neotropical (Mondolfi 1972, Matamoros 1982, Silva 1984); os machos adultos medem $60-80 \mathrm{~cm}$, do focinho à ponta da cauda, e as fêmeas, $55-70 \mathrm{~cm}$, de acordo com Mondolfi (1972) e Bentti (1981). O peso corpóreo varia de $5-10 \mathrm{~kg}$, podendo chegar até aos $14 \mathrm{~kg}$, de acordo com Matamoros (1982), embora Deutsch \& Puglia (1988) não tenham encontrado espécimes maiores do que $10 \mathrm{~kg}$.

A cutia é um mamífero que pertence à mesma família da paca, no entanto, é um animal de pequeno porte, do gênero Dasyprocta e espécie Dasyprocta aguti, Linnaeus, 1766. Em geral, possui tamanho de $49-64 \mathrm{~cm}$, apresenta apenas vestígio de cauda e, extremidades torácicas bem mais curtas que as pélvicas com 5 dígitos cada, sendo que três são mais desenvolvidos, com unhas cortantes equivalentes a pequenos cascos e um quinto dígito é muito reduzido (Bentti 1981).

Estudos envolvendo a placentação e os anexos fetais de roedores são de fundamental importância, principalmente quando visam o estabelecimento de modelos experimentais. Björkman et al. (1989) relataram que os roedores, por apresentarem algumas características peculiares, tais como tamanho adequado, preço acessível e curto período de prenhez, são considerados animais experimentais ad hoc. A obtenção de informações sobre os aspectos reprodutivos de roedores como a paca e a cutia também oferecem subsídios para a produção racional e, conseqüente preservação das espécies, que possuem importância como fonte de proteína animal a populações rurais. Digno de nota é que nas regiões em que habitam, pacas e cutias vêm sendo exploradas indiscriminadamente, levando a redução na densidade da população destas espécies (Hamelett \& Rasweiler IV 1993).

Em vista disso, o presente trabalho visou caracterizar macro e microscopicamente o saco vitelino em duas espécies de roedores da subordem Hystricomorpha, Paca (Agouti paca) e Cutia (Dasyprocta aguti).

\section{MATERIAL E MÉTODOS}

Utilizaram-se nesse trabalho embriãos/fetos de 3 pacas (Agouti paca) cedidos pela Unesp-Jaboticabal, sob o processo IBAMA 02154.002524/24-67, e 3 cutias (Dasyprocta aguti) cedidas pelo Cemas (Centro de Multiplicação de Animais Silvestres da Escola Superior de Agricultura de Mossoró, RN), com registro no IBAMA sob $n^{\circ}$ 12.492-0004. A nomenclatura utilizada foi referida conforme o International Commitee on Veterinary Gross Anatomical Nomenclature.

Coleta do material. Após identificação da prenhez, através de sessões de ultra-sonografia $B$, usando-se transdutor bifreqüencial setorial eletrônico de 5,0 e $7,5 \mathrm{MHz}$, os animais que se encontravam no início da gestação foram destinados os processos cirúrgicos. Em seguida obtinha-se o peso individual de cada animal (5-10 kg), fazendo-se a aplicação de tranqüilizantes, anestésicos, analgésicos e antibióticos, por via intramuscular (IM), no membro pélvico. A tranqüilização foi obtida através da aplicação de azaperone $(4 \mathrm{mg} / \mathrm{kg})$ pela via (IM). Após 10 minutos, foram aplicados $0,06 \mathrm{mg} / \mathrm{kg}$ de sulfato de atropina pela via IM. A indução da anestesia foi obtida após 15 minutos da administração de sulfato de atropina na associação de cloridratos de quetamina $(20 \mathrm{mg} / \mathrm{kg})$ e de xilazina $(1,5 \mathrm{mg} / \mathrm{kg})$ para indução da anestesia. Após o tempo de latência, o animal era colocado em decúbito e iniciava-se na região abdominal ampla tricotomia, seguida a indução da anestesia geral com halotano. A incisão foi feita no sentido pré-retroumbilical, de forma a expor o útero gravídico, que era então caracterizado macroscopicamente; identificava-se o corno gestante, incisavase o mesmo, e, após exposição do conjunto de anexos embrionários e embrião/feto, procedia-se à caracterização macroscópica das estruturas. Após os procedimentos cirúrgicos, os animais foram mantidos em gaiolas individuais e submetidos a antibioticoterapia: amoxilina $(22 \mathrm{mg} / \mathrm{kg})$ por via intramuscular a cada 24 horas durante sete dias.

Microscopia de luz. Os anexos fetais contendo o saco vitelino foram cuidadosamente retirados dos embriões/fetos fixados em solução de formaldeído a $10 \%$ e paraformaldeído a $3 \%$ e processados rotineiramente para inclusão em parafina (Histosec-Merckâ, Lote K91225309), de acordo com Tolosa et al. (2003). No momento da inclusão das amostras, os fragmentos de tecido foram orientados de modo a permitir durante a microtomia secções transversais e longitudinais do saco vitelino. Cortes histológicos de cerca de $5 \mathrm{~mm}$ de espessura foram obtidos em um micrótomo LEICA RM 2165 e colhidos em lâminas de vidro. As secções foram então coradas com Tricômio de Masson (Junqueira et al. 1979) e Hematoxilina-Eosina (HE) (Tolosa et al. 2003) e analisadas e fotografadas em microscópio de luz (Nikon Eclipse E-800).

Microscopia eletrônica de transmissão. Os anexos fetais do saco vitelino foram recortados e fixados em glutaraldeído 
2,5\% em tampão fosfato $0,1 \mathrm{M}, \mathrm{pH}$ 7,3. Após lavagem no mesmo tampão, as amostras foram pós-fixadas em tetróxido de ósmio (osmium tetroxide solution in water, Polyscience, Inc. USA) a $2 \%$ por 1 hora e posteriormente contrastadas com acetato de uranila a 3\% sob agitação, por uma hora, em câmara escura. 0 material foi então desidratado em séries crescentes de etanol, seguido por banhos sequenciais de óxido de propileno (Propylene oxide EM Grade-Polysciences Inc., USA), óxido de propileno-resina (de proporção 1:1) e finalmente apenas resina Spurr (Spurr's kit-Electron Microscopy Sciences, Co., USA). Os materiais foram então incluídos e submetidos ao vácuo por 30 minutos. Após a polimerização da resina, os blocos foram cortados em um ultramicrótomo (Leica ULTRACUT UCT ${ }^{\circledR}$ ), contrastados com acetato de uranila a $2 \%$ em água destilada (5 minutos) e pelo citrato de chumbo a $0,5 \%$ em água destilada (10 minutos) e analisados nos microscópios eletrônicos de transmissão Zeiss® EM-94S2 e JEOL CX-II-100.

\section{RESULTADOS E DISCUSSÃO}

Em mamíferos superiores, a ocorrência das quatro membranas extra-embrionárias é um fato tido como comum a todas as espécies. Estas membranas, no entanto, podem sofrer modificações morfológicas, interagindo entre si e formando complexos funcionais ou mesmo involuindo com o decorrer da gestação (Oliveira et al. 2006).
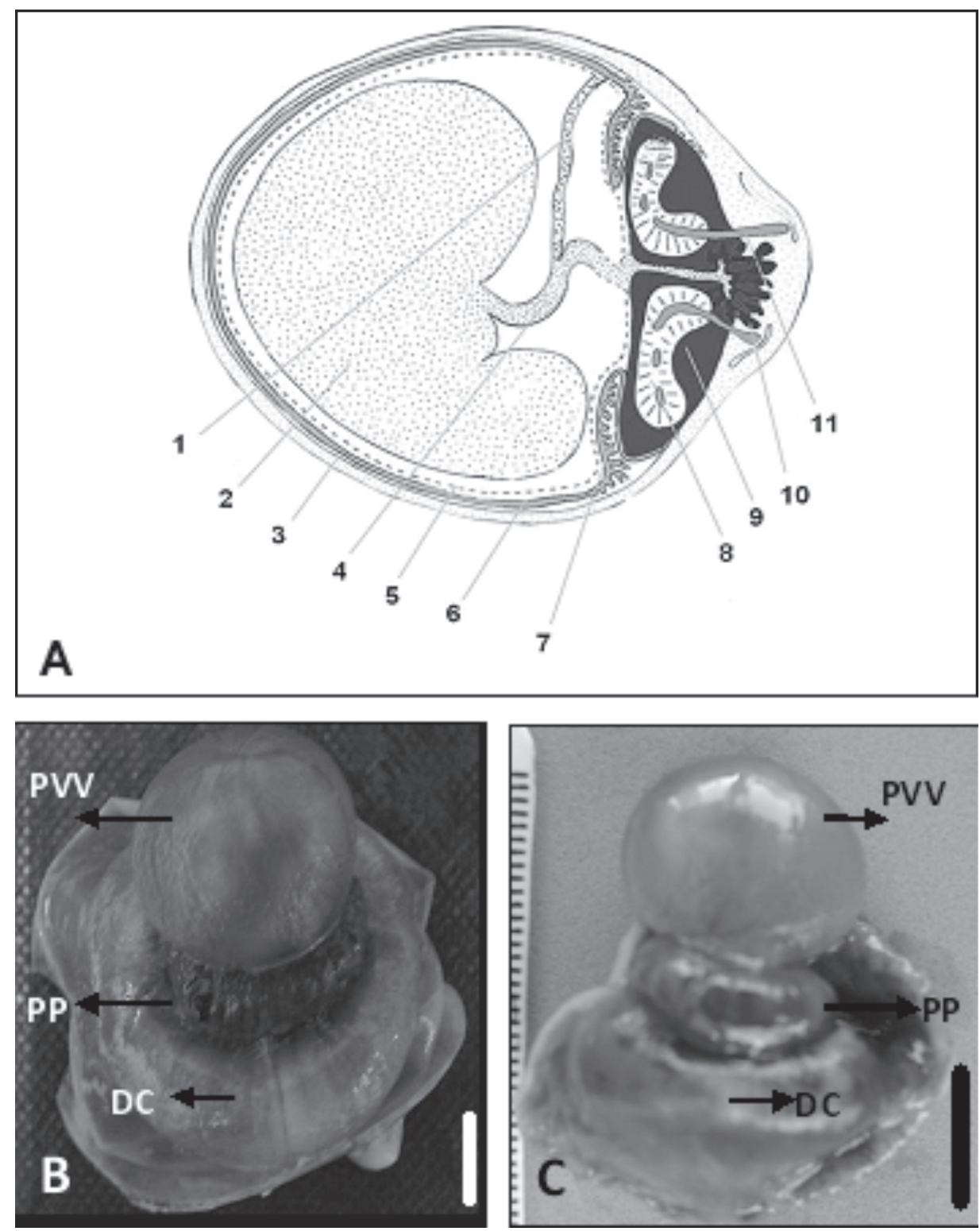

Fig.1. Placenta em roedores hystricomorfos. A. Esquema ilustrativo da placenta em roedores da subordem Hystricomorpha. Adaptado por Rogério Arcuri Conceição (Disponível em: http://medicine.ucsd.edu/cpa), no qual, os números indicam estruturas placentárias: 1-Vascularização da placenta vitelínica; 2-Feto; 3-Parede uterina; 4-Cordão umbilical; 5-Âmnio; 6-Placenta vitelínica visceral; 7-Placenta vitelínica parietal; 8-Labirinto; 9-Interlóbulo; 10-Subplacenta; 11-Artéria materna. B. Placenta em pacas: placenta vitelínica visceral (PVV), placenta principal ou córioalantóica (PP) e decídua capsular (DC). C. Placentação em cutias: evidencia as mesmas estruturas apresentadas na placenta de paca. Em "B" e "C" barras de $1 \mathrm{~cm}$. 
Na maioria dos roedores o saco vitelino sofre um processo de inversão junto à placenta principal, formando a placenta vitelínica, um anexo da placenta corioalantoideana e da subplacenta. A essa inversão do saco vitelino na paca e cutia, nossos resultados corroboram com os trabalhos envolvendo outros roedores sul-americanos segundo Silva (2001) para paca, Ferraz (2001) para capivara e Oliveira et al. (2006) para mocós (Fig.1). Notamos ainda que a mesma estrutura embrionária apresentava-se intensamente vascularizada, a exemplo dos outros roedores como Tupaia glis (Lucket 1968), Castor canadensis (Fischer 1971), cutia (Rodrigues et al. 2003) e nos demais mamíferos (Leiser \& Kaufmann 1994).

Em nossos estudos para ambas as espécies, notamos outra característica marcante aos roedores, a fusão do cório e o alantóide, simulando uma só membrana. Esta fusão observada entre esses dois anexos, a chamada placenta corioalantoideana, vai de encontro ao descrito por Silva (2001) e Bonatelli et al. (2005), para a paca, Oliveira et al. (2006) para o mocó, Ferraz (2001) para capivara e Rodrigues et al. (2003) para cutia.

A placenta principal de ambos os animais apresentava a forma de cálice, com coloração a fresco avermelhada e relacionava-se no sentido materno, com a subplacenta centralmente e com a decídua basal lateralmente (Fig.2A,B).

Estruturalmente a placenta principal, mostrou-se composta por lóbulos e áreas entre estes denominadas interlóbulos. Cada lóbulo da placenta era constituído por duas regiões, a área central do lóbulo e o labirinto (Fig.2A,B). Estas características foram evidenciadas até o período de final de gestação. Os lobos placentários apresentaram cor mais escura seguida de regiões de coloração mais clara, que por sua vez, caracterizava as regiões dos interlóbulos (regiões intermediárias que delimita cada lobo). A organização lobular da placenta foi descrita em detalhes nesta espécie por Bonatelli (2001), para o mocó por Oliveira et al. (2006), para a cutia por Rodrigues et al. (2003) e para a capivara por Ferraz (2001).

Análises microscópicas do saco vitelino da paca e da cutia mostraram que este órgão pode ser dividido entre duas porções: placenta vitelínica parietal (Fig.3A,B,C,D) e uma visceral (Fig.4 e 5), diferindo portanto, dos resultados obtidos por Tibbitts \& Hillemann (1959) em chinchila, que não observaram placenta vitelínica parietal nem membrana de Reichert se formando nestes animais. Ao contrário da paca e semelhante ao observado por estes autores, também não observamos membrana de Reichert na cutia.

As placentas vitelínicas viscerais da paca e da cutia apresentaram algumas diferenças entre si; na análise ultraestrutural estas eram constituídas por células endodérmicas com núcleos dispostos apicalmente na cutia, enquanto, que na paca os núcleos apresentavam-se na região mediana, geralmente contendo um único e proeminente nucléolo (Fig.6A,B). Diferentemente ao descrito na cobaia (King \& Enders 1970) e no mocó por Oliveira et al. (2006), estes citam que as células endodérmicas apresentavamse com os núcleos dispostos basalmente e contendo um único nucléolo.

O mesoderma vitelino mostrou-se constituído de tecido mesenquimal (conjuntivo fetal) (Fig.6A), permanecendo este em contato direto com a placenta, formando 0 mesoderma vitelino visceral. O mesmo pode ser observado na placenta de mocó (Oliveira et al. 2006), o qual descreveu que este tecido de origem extra-embrionário possui vasos sangüíneos que irão transportar os elementos oriundos das células endodérmicas da placenta para o embrião/feto.

Em ambos os animais, o citoplasma mostrou-se muito
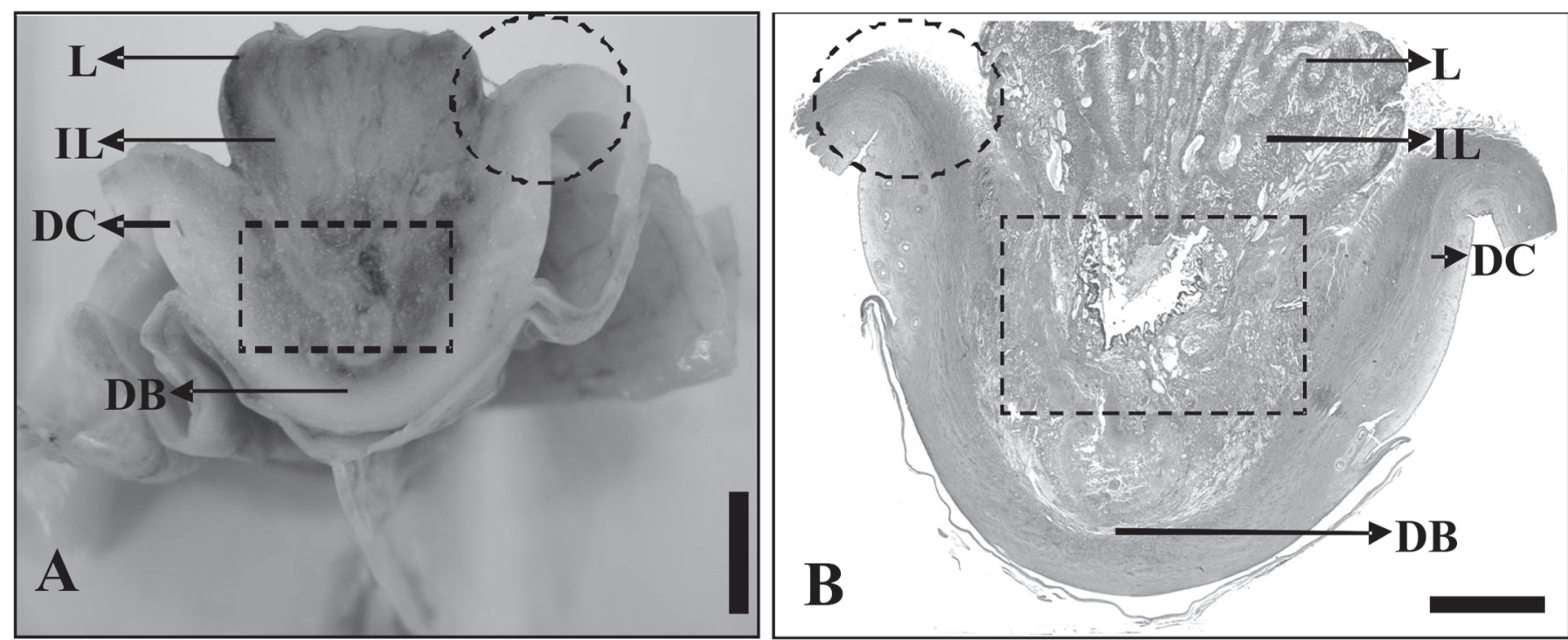

Fig.2. Placenta Principal de paca, fase inicial de gestação, (A) evidenciando de maneira macro e (B) de maneira microscópica, as distintas regiões: região da placenta vitelínica parietal (circulo), região da subplacenta (quadrado), decídua basal (DB), decídua capsular (DC) e a placenta principal organizada em lóbulos (IL = região do interlóbulo; $\mathrm{L}=$ região do lóbulo). (A) Barra: $1 \mathrm{~cm}$. (B)

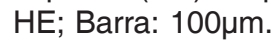



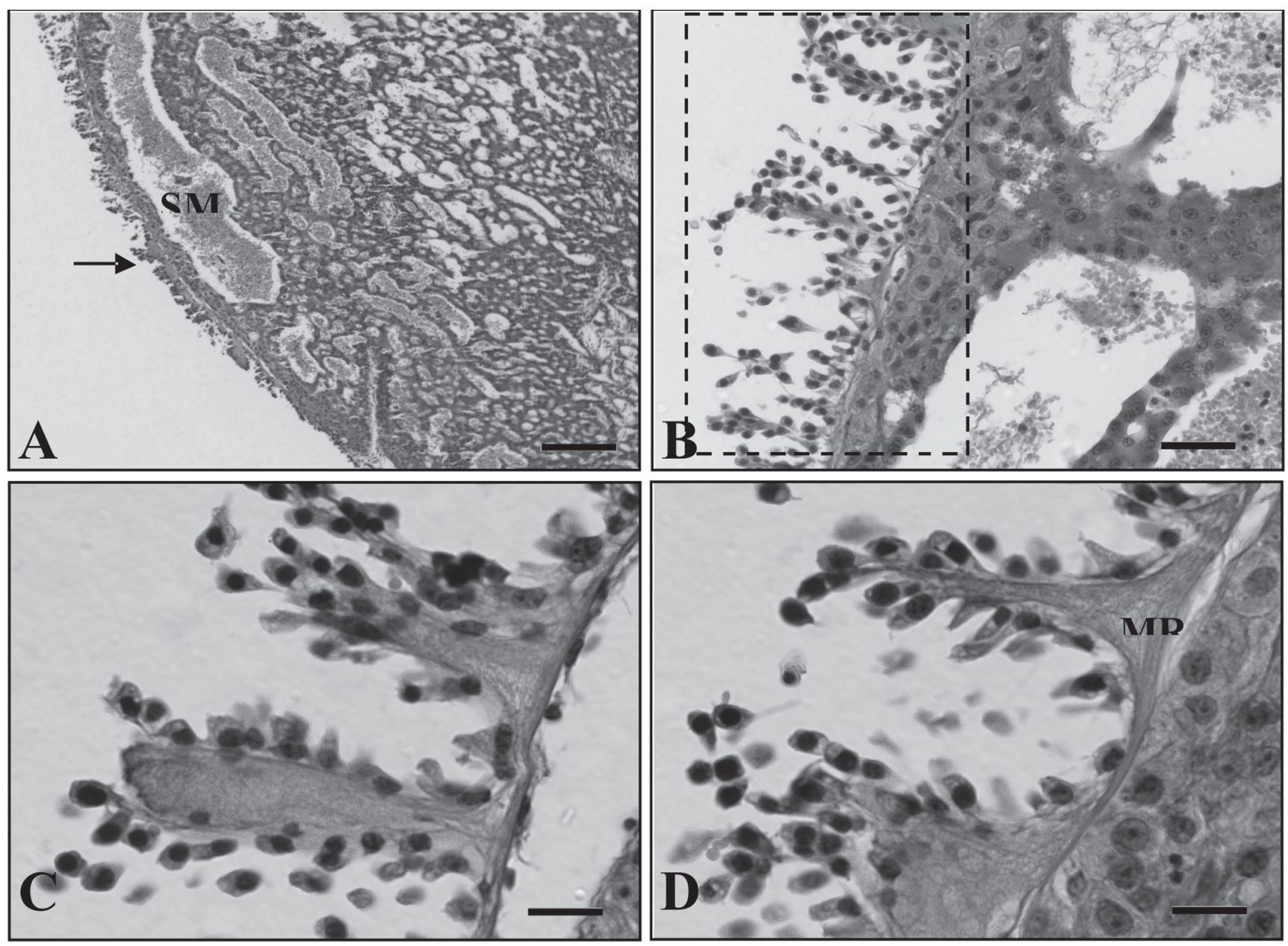

Fig.3. Placenta Principal e Placenta Vitelínica Parietal de paca nas fases iniciais da gestação. (A) Área de junção entre a Placenta Principal e a Placenta Vitelínica Parietal $(\rightarrow)$. (B) Vilosidades da placenta vitelínica parietal. (C) Detalhes das vilosidades. (D)

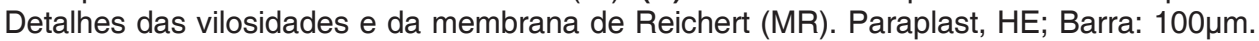

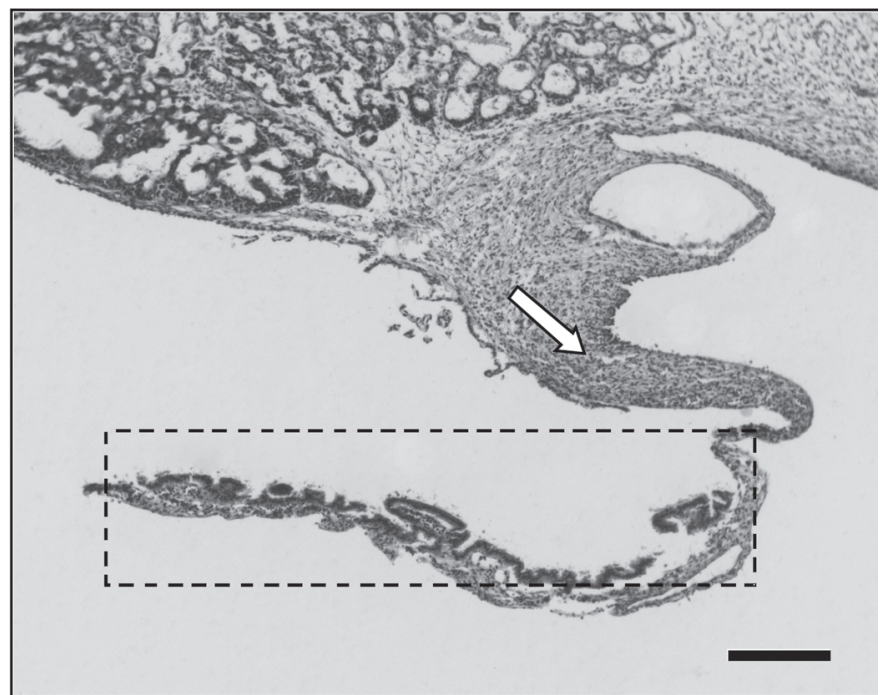

Fig.4. Porção visceral da placenta vitelínica da paca. Em destaque o apêndice $(\rightarrow)$ pelo qual a Placenta Vitelínica Visceral (quadrado) prende-se à placenta corioalantoídea. Barra: $100 \mu \mathrm{m}$.

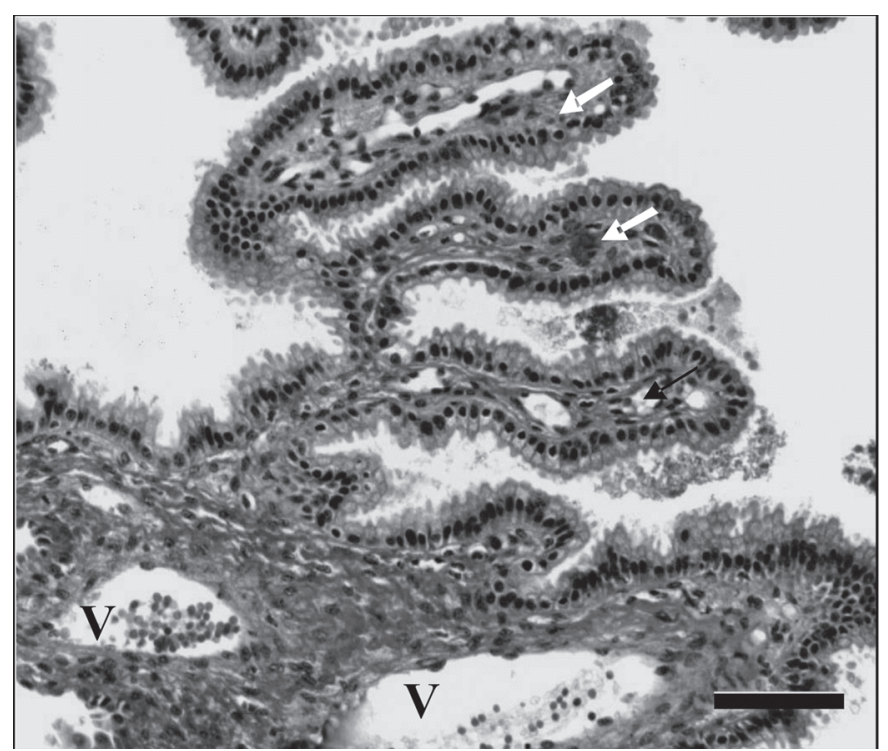

Fig.5. Placenta vitelínica visceral de cutia. Em destaque, vilosidades $(\leftarrow)$ e vasos sanguíneos $(V)$. Tricômio de Masson; Barra: $100 \mu \mathrm{m}$. 

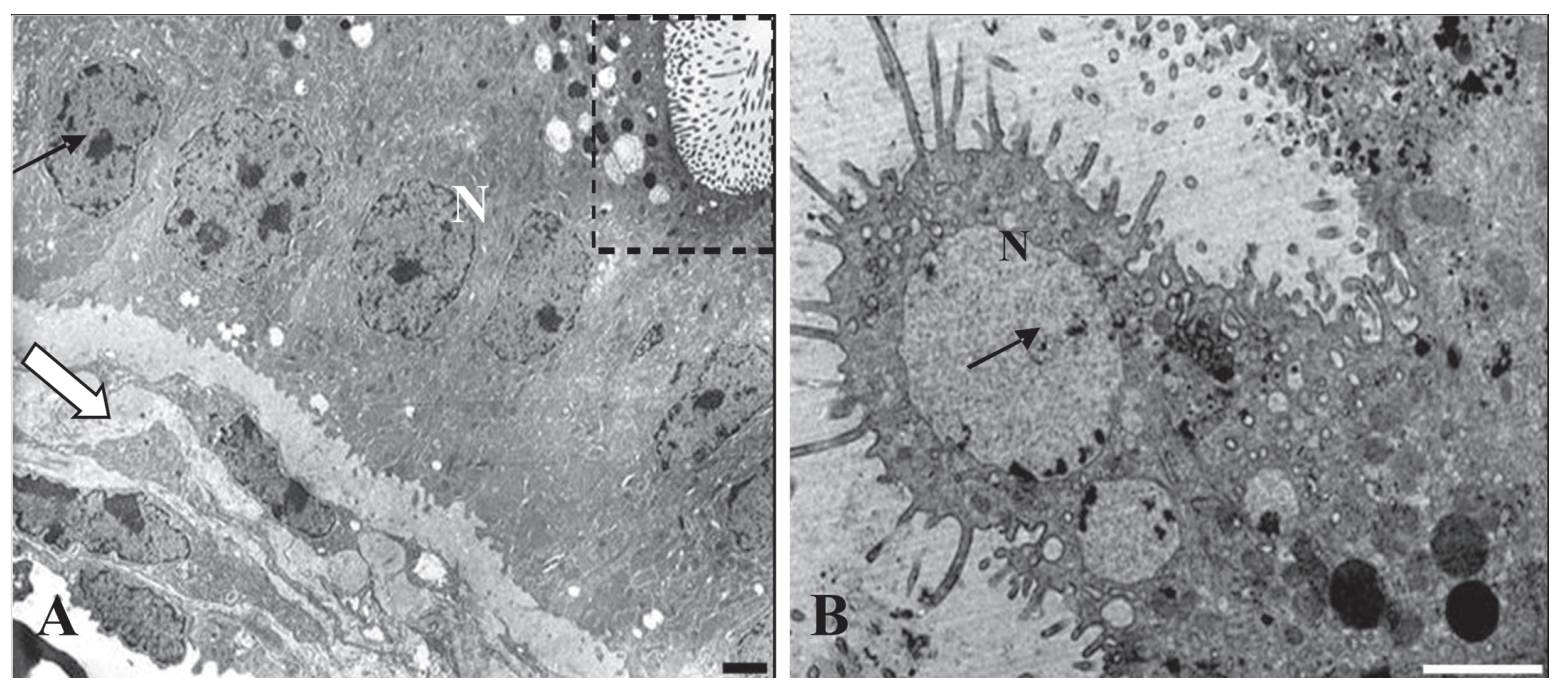

Fig.6. Eletromicrografias da placenta vitelínica visceral de paca e de cutia. (A) Placenta vitelínica visceral de paca. Notar a presença de células endodérmicas com núcleos em posição mediana celular [N], a presença, geralmente de um nucléolo por célula (seta fina) e o mesoderma vitelino (seta larga). Na superfície celular, inúmeras microvilosidades podem ser observadas (quadrado). (B) Placenta vitelínica visceral de cutia, onde uma célula endodérmica em destaque apresenta núcleo na região apical celular. Barras: 2.500x.

volumoso com cisternas do retículo endoplasmático bem desenvolvidas.

Também nas duas espécies, observou-se grande número de mitocôndrias e vesículas de conteúdo eletrodenso

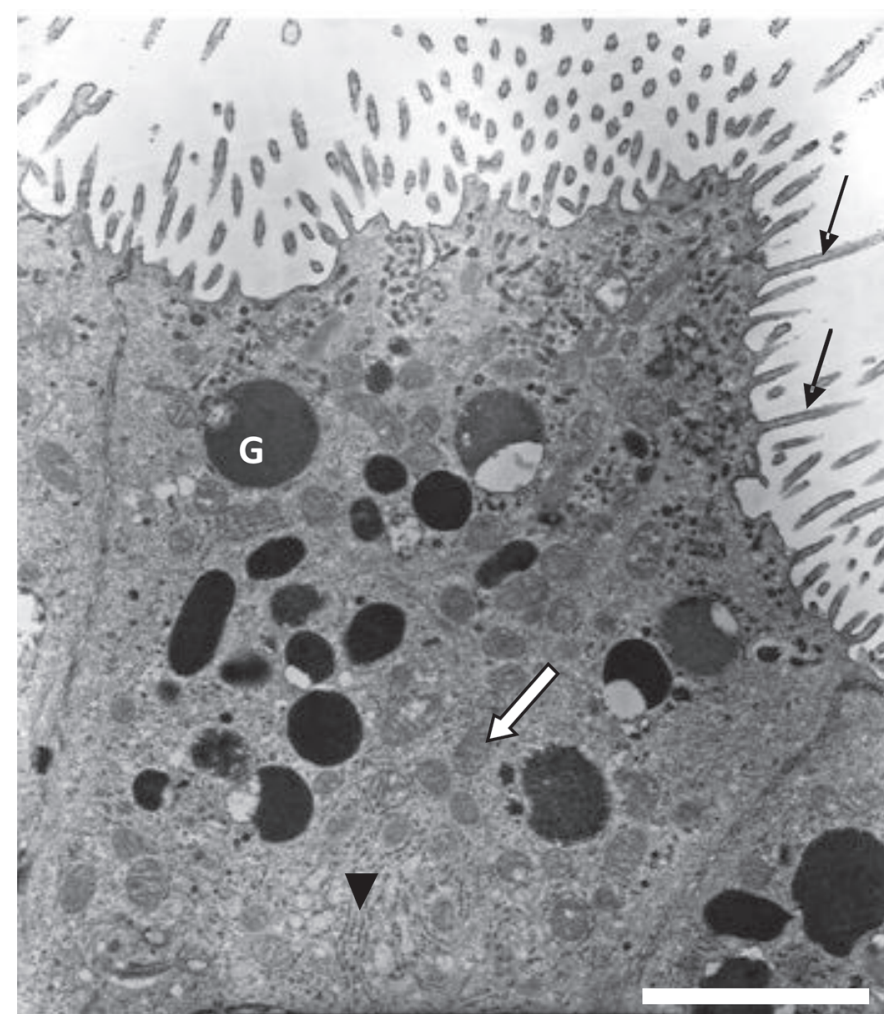

Fig.7. Eletromicrografia da placenta vitelínica da paca. Em destaque microvilos (setas), grânulos eletrodensos (G), mitocôndrias (seta cheia) e retículo endoplasmático (cabeça de seta). Barra: 7.000x. com formas diversas e, em sua grande maioria, dispostas na região supranuclear. As células desta região também se caracterizaram pela grande quantidade de microvilosidades na face voltada para a parede uterina, ou seja, em contato com o sangue materno (Fig.7). Esses resultados vão ao encontro daqueles expostos por Oliveira et al. (2006) para o mocó e por Bonatelli et al. (2005) para a paca.

\section{CONCLUSÕES}

A placenta vitelínica das duas espécies estudadas apresentou inserção na superfície da placenta principal e projeções marginais sobrepondo completamente o embrião. Assim como descrito para outras espécies, o epitélio endodérmico recobriu o mesoderma extra-embrionário vascularizado pelos vasos vitelínicos.

A placenta vitelínica da paca apresentou-se sustentada pela membrana de Reichert ao contrário da cutia, que não possui tal membrana.

O cório e o alantóide, em ambos os roedores estudados, estiveram justapostos, junto à placenta principal, formando a placenta corioalantoídea.

O saco vitelino em ambas as espécies apresentou-se invertido e vascularizado, como nos demais roedores sulamericanos.

Agradecimentos.- À FAPESP pelo auxílio financeiro (Proc.06/610033), à Faculdade de Medicina Veterinária e Zootecnia (FMVZ) da Universidade de São Paulo (USP) e ao Centro Universitário da Fundação de Ensino Octávio Bastos (Unifeob) pelo suporte técnico.

\section{REFERÊNCIAS}

Bentti S.B. 1981. Roedores da América Tropical. Natura 70(1):40-44. Björkman N., Dantzer V. \& Leiser R. 1989. Comparative placentation in laboratory animals: A review. Scand. J. Anim. Sci. 16(4):129-158.

Bonatelli M. 2001. Análise morfológica da placenta da paca (Agouti paca L. 
1766). Estudo microscópio de luz e microscopia eletrônica de transmissão. Dissertação de Mestrado em Anatomia dos Animais Domésticos, Faculdade de Medicina Veterinária e Zootecnia, USP, São Paulo. 68p.

Bonatelli M., Carter A.M., Machado M.R.F., Oliveira M.F., Lima M.C. \& Miglino M.A. 2005. Placentation in the paca (Agouti paca L.). Reprod. Biol. Endocrinol. 3(9):1-12.

Deutsch L.A. \& Puglia L.R.R. 1988. Paca, p.45-50. In: Deutsch L.A. \& Puglia L.R.R. (ed.), Os Animais Silvestres: Proteção, doenças e manejo. Editora Globo, Rio de J., 191p.

Ferraz R.H.S. 2001. Estudo macro e microscópico da placenta de termo de capivara (Hidrochaeris hydrochaeris, Carleton, M.D.) Tese de Doutorado em Anatomia dos Animais Domésticos, Faculdade de Medicina Veterinária e Zootecnia, USP, São Paulo. 75p.

Fischer T.V. 1971. Placentation in the American beaver (Castor canadensis). Am. J. Anat. 131(2):159-184.

Hamelett W.C. \& Rasweiler IV J.J. 1993. Comparative gestation and placentation in vertebrates. J. Exper. Zool. 266:343-346.

Junqueira L.C.U., Bignolas G. \& Bretani R.R.1979. Picrosirius staining plus polarization microscopy, a specific method for collagen detection in the tissue sections. Histochem. J. 11(4):447-455.

King B.F. \& Enders A.C. 1970. The fine structure of the guinea-pig visceral yolk sac placenta. Am. J. Anat. 127(4):397-414.

Leiser R. \& Kaufmann P. 1994. Placental structure: in a comparative aspect. Exper. Clin. Endocrinol. 102(3):122-134.
Luckett W.P. 1968. Morphogenesis of the placenta and fetal membranes of the tree shrews (Family Tupaiidae). Am. J. Anat. 123(3):385-428.

Matamoros Y. 1982. Notas sobre la biologia del tepezcuinte, Cuniculus paca Brisson, (Rodentia: Dasyproctidae) en cautiverio. Brenesia 19/ 20:71-82.

Mondolfi E. 1972. La laca o paca. Defensa de la Naturaleza 2(5):4-16.

Moojen J. 1962. Os Roedores do Brasil. Biblioteca Científica Brasileira. Série A, II, Instituto Nacional do Livro, Ministério de Educação e Saúde, Rio de Janeiro. 214p.

Oliveira M.F., Carter A.M., Bonatelli M., Ambrósio C.E. \& Miglino M.A. 2006. Placentation in the rock cavy, Kerodon rupestris (Wied). Placenta 27(1):87-97.

Rodrigues R.F., Miglino M.A., Ferraz R.H.S. \& Morais-Pinto L. 2003. Placentação em cutias (Dasyprocta aguti, Carleton, M.D.): aspectos morfológicos. Braz. J. Vet. Res. Anim. Sci. 40(2):133-137.

Silva W.M. 2001. Aspectos morfológicos da placenta e anexos fetais da paca (Agouti paca Linnaeus 1766). Dissertação de Mestrado em Anatomia dos Animais Domésticos, Faculdade de Medicina Veterinária e Zootecnia, USP, São Paulo. 61p.

Tibbits F.D. \& Hillemann H.H. 1959. The development and histology of the chinchilla placenta. J. Morphol. 105:317-365.

Tolosa E.M.C., Rodrigues C.J., Behmer O.A. \& Freitas-Neto A.G. 2003. Manual de técnicas para histologia normal e patológica. $2^{\mathrm{a}}$ ed. Manole, São Paulo, p.331. 